\title{
Erratum
}

Cold Spring Harb Protoc 2013; doi: 10.1101/pdb.prot075176

\section{Erratum: Preparation of Nuclear Extracts from HeLa Cells}

Timothy W. Nilsen

When this protocol was first published, the recipes entitled "Buffer B (Low Salt)" and "Buffer C (High Salt)" contained errors. The stock concentration of glycerol used in Buffer B (Low Salt) should have been expressed as " $50 \%$," not as " $50 \mathrm{~mL}$," and the final concentration of $\mathrm{KCl}$ in Buffer C (High Salt) should have been listed as "1.2 M," not as "1.2 mм." Corrected versions of these recipes are below, and the HTML versions of the recipes and the PDF version of the protocol have been amended accordingly.

Buffer B (Low Salt)

\begin{tabular}{lrc} 
Reagent & $\begin{array}{c}\text { Quantity } \\
\text { (for } 100 \mathrm{~mL})\end{array}$ & $\begin{array}{c}\text { Final } \\
\text { concentration }\end{array}$ \\
\hline Tris- $\mathrm{HCl}(1 \mathrm{M}, \mathrm{pH} 7.9)$ & $2 \mathrm{~mL}$ & $20 \mathrm{~mm}$ \\
Glycerol $(50 \%$, ultrapure) & $50 \mathrm{~mL}$ & $25 \%(\mathrm{v} / \mathrm{v})$ \\
$\mathrm{MgCl}_{2}(1 \mathrm{M})$ & $0.15 \mathrm{~mL}$ & $1.5 \mathrm{~mm}$ \\
EDTA $(0.5 \mathrm{M}, \mathrm{pH} 8.0)$ & $0.04 \mathrm{~mL}$ & $0.2 \mathrm{~mm}$ \\
$\mathrm{KCl}(3 \mathrm{M})$ & $0.66 \mathrm{~mL}$ & $20 \mathrm{~mm}$ \\
$\mathrm{H}_{2} \mathrm{O}$ & to $100 \mathrm{~mL}$ &
\end{tabular}

Store at $4^{\circ} \mathrm{C}$.

Buffer C (High Salt)

Quantity Final

Reagent (for $100 \mathrm{~mL}$ ) concentration

Tris- $\mathrm{HCl}(1 \mathrm{~m}, \mathrm{pH}$ 7.9)

Glycerol (ultrapure, 50\%, v/v)

$20 \mathrm{~mm}$

$\mathrm{MgCl}_{2}(1 \mathrm{~m})$

$\begin{array}{cc}2 \mathrm{~mL} & 20 \mathrm{mM} \\ 50 \mathrm{~mL} & 25 \%(\mathrm{v} / \mathrm{v}) \\ 0.15 \mathrm{~mL} & 1.5 \mathrm{mM} \\ 0.04 \mathrm{~mL} & 0.2 \mathrm{mM} \\ 40 \mathrm{~mL} & 1.2 \mathrm{M}\end{array}$

$\mathrm{KCl}(3 \mathrm{M})$

to $100 \mathrm{~mL}$

$\mathrm{H}_{2} \mathrm{O}$

Store at $4^{\circ} \mathrm{C}$ 


\section{Erratum: Preparation of Nuclear Extracts from HeLa Cells}

Timothy W. Nilsen

Cold Spring Harb Protoc; doi: 10.1101/pdb.err094813

\begin{aligned} & \hline $\begin{array}{r}\text { Email Alerting } \\ \text { Service }\end{array}$ Receive free email alerts when new articles cite this article - click here. \\ & \hline $\begin{array}{r}\text { Subject } \\ \text { Categories }\end{array}$ Browse articles on similar topics from Cold Spring Harbor Protocols. \\ & \hline\end{aligned}

